Article

\title{
Rhodotorula Strains Isolated from Seawater That Can Biotransform Raw Glycerol into Docosahexaenoic Acid (DHA) and Carotenoids for Animal Nutrition
}

\author{
Natalie L. Pino-Maureira ${ }^{1,2,3, *}$, Rodrigo R. González-Saldía ${ }^{1,2,3}$, Alejandro Capdeville ${ }^{4}$ and Benjamín Srain ${ }^{3}$ \\ 1 Doctorado en Ciencias con Mención en Manejo de Recursos Acuáticos Renovables (MaReA), \\ Facultad de Ciencias Naturales y Oceanográficas, Universidad de Concepción, Concepción 4070405, Chile; \\ rogonzal@udec.cl \\ 2 Departamento de Oceanografía, Facultad de Ciencias Naturales y Oceanográficas, \\ Universidad de Concepción, Concepción 4070405, Chile \\ 3 Centro de Investigación Oceanográfica COPAS Sur-Austral, Facultad de Ciencias Naturales y Oceanográficas, \\ Universidad de Concepción, Concepción 4070405, Chile; bsrain@udec.cl \\ 4 EWOS Chile, Alimentos Ltd.a., Parque Industrial, Escuadrón Km 20, Coronel 4190000, Chile; \\ alejandro.capdeville.s@gmail.com \\ * Correspondence: napino@udec.cl; Tel.: +56-41-2983651
}

check for updates

Citation: Pino-Maureira, N.L.; González-Saldía, R.R.; Capdeville, A.; Srain, B. Rhodotorula Strains Isolated from Seawater That Can Biotransform Raw Glycerol into Docosahexaenoic Acid (DHA) and Carotenoids for Animal Nutrition. Appl. Sci. 2021, 11, 2824. https://doi.org/10.3390/ app11062824

Academic Editor: Marco F. L. Lemos

Received: 12 February 2021

Accepted: 5 March 2021

Published: 22 March 2021

Publisher's Note: MDPI stays neutral with regard to jurisdictional claims in published maps and institutional affiliations.

Copyright: (c) 2021 by the authors. Licensee MDPI, Basel, Switzerland. This article is an open access article distributed under the terms and conditions of the Creative Commons Attribution (CC BY) license (https:/ / creativecommons.org/licenses/by/ $4.0 /)$.
Featured Application: Marine biomass of Rhodotorula could be used as an alternative source of PUFAs and carotenoids for human and animal nutrition, using raw glycerol for their culture.

\begin{abstract}
Due to the overexploitation of industrial fisheries, as the principal source of fish oil, as well as the increasing replacement of synthetic pigments for animal nutrition, we need to find sustainable sources for these essential nutrient productions. Marine Rhodotorula strains NCYC4007 and NCYC1146 were used to determine the biosynthesis of docosahexaenoic acid (DHA) and carotenoids by biotransforming raw glycerol, a waste product of biodiesel. To evaluate the presence of inhibitory substances in raw glycerol, both strains were also grown in the presence of analytical grade glycerol and glucose as the main carbon source separately. With raw glycerol, NCYC4007 showed a significant correlation between DHA production and intracellular phosphorous concentrations. NCYC1146, a new Rhodotorula strain genetically described in this work, can produce canthaxanthin but only when glycerol is used as a main carbon source. Then, NCYC4007 could synthesize DHA as a phospholipid, and the production of canthaxanthin depends on the kind of carbon source used by NCYC1146. Finally, malate dehydrogenase activity and glucose production can be used as a proxy of the metabolisms in these marine Rhodotorula. This is the first evidence that marine Rhodotorula are capable of synthesizing DHA and canthaxanthin using an alternative and low-cost source of carbon to potentially scale their sustainable production for animal nutrition.
\end{abstract}

Keywords: Rhodotorula sp.; docosahexaenoic acid (DHA); carotenoids; canthaxanthin; raw glycerol

\section{Introduction}

Rhodotorula species are pigmented basidiomycetous yeasts in the family Sporidiobolaceae [1]. This genus contains 37 species, and only three of them, including $R$. mucilaginosa (formerly R. rubra), R. minuta, and $R$. glutinis, have been reported as causes of infection in humans [2]. Most species of Rhodotorula have been isolated from terrestrial ecosystems, which can metabolize diverse carbon sources. From the marine environment, the Rhodotorula described: $R$. glutinis, $R$. glutinis var. dairiensis, $R$. aurantiaca, $R$. graminis, $R$. (mucilaginosa) rubra, $R$. pilimanae, $R$. minuta and $R$. aurea are capable of metabolizing substrates such as galactose, lactose, maltose, sucrose, melibiose, raffinose, turanose, melezitose and cane molasses [3-5], and Rhodotorula glutinis, R. mucilaginosa, and $R$. gracilis are able to 
use glycerol and potato wastewater as a carbon source [6-8] but in low concentration of sodium $(\leq 1.1 \%)$.

From the marine ecosystem of the Southeastern Pacific twelve strains of marine fungoids capable of producing DHA, EPA and carotenoid pigments have been isolated [9]. In particular, the NCYC4007 yeast strain, characterized at the molecular level as a Rhodotorula strain, has been highlighted for its high production of DHA and carotenoids ( $23 \%$ and $11 \%$ dried weight, respectively) when the commercial Sabouraud medium (SM) was used [9]. This strain has been successfully used for fish larvae nutrition [10]. Additionally, in SM, a marine yeast from the Southern Austral marine ecosystem of Chile (strain NCYC1146), characterized as a high producer of carotenoids, was isolated. However, the genetic identity at the molecular level of this strain must be determined.

The strains NCYC4007 and NCYC1146 isolated from seawater seem to be promising candidates for the biotechnological production of DHA and carotenoid pigments. However, a crucial step to use them in that way needs to sort out the problem of the scaling the production using alternatives source of carbon with a lower price than commercial growing media (i.e., Sabouraud media). At the same time, the raising of the production of these substances to an industrial level needs to satisfy that higher economic, environmental and social sustainability can be reached.

In bioprocesses, raw glycerol is an important material for the economic viability of diverse fermentation processes. It is employed as alternative source of carbon different from glucose, due to the abundance and low cost. Among these are the production of substances of microbial origins such as 1, 3-propanediol, citric acid, succinic acid, polyhydroxyalkanoates and rhamnolipids by bacteria [11]; DHA and EPA by Thraustochytrids [12-18]; and lipids and carotenoid pigments by yeast isolated from terrestrial ecosystem [16-18]. Yeast isolated from seawater such as Yarrowia lipolytica has been cultivated using raw glycerol [19], although $R$. marina, a marine yeast member of the Rhodotorula genus, has not been cultivated using this raw substrate [17]. Other Rhodotorula members such as R. glutinis and $R$. toruloides, have been cultivated using raw glycerol [14,17]; however, they have not been isolated from seawater, and they require freshwater to grow.

In the present study, the capability of the marine Rhodotorula strain NCYC4007 and the marine yeast strain NCYC1146 to grow using raw glycerol in seawater and produce DHA and carotenoids was determined. To evaluate the presence of inhibitory substances in raw glycerol, both strains were grown in a medium with analytical grade glycerol and compared with the use of glucose as the main carbon source. The variables of the biomass production, DHA, total carotenoids and kinetic growth parameters were assessed. Subsequently, the fatty acid profile; carotenoid pigments; live microbial biomass and other metabolic parameters (glucose, phosphorus, cholesterol content and enzymatic activity of malate and lactate dehydrogenase) for both strains were characterized. Finally, the genetic characterization at the molecular level of the strain NCYC1146 was determined.

\section{Materials and Methods}

\subsection{Molecular Genotyping of the NCYC 1146 Strain through 18s rRNA Gene Sequence}

DNA extraction from the NCYC 1146 strain was performed using Ultra Clean ${ }^{\circledR} \mathrm{Mi}-$ crobial DNA Isolation (MO BIO Laboratories INC.) (Carlsbad, CA, USA) following the supplier's instructions. DNA was stored at $-20^{\circ} \mathrm{C}$.

The amplification of the ribosomal gene 18s rRNA was carried out by PCR, using the primers described $18 \mathrm{~S} 1$ (5'-AACCTGGTTGATCCTGCCAGTA-3') and $18 \mathrm{~S} 12\left(5^{\prime}\right.$ CCITGTTACGACITCACCTTCCTCT- $3^{\prime}$ ) [18]. Reaction mixture contained the following reagents: $5 \times$ buffer of dNTPs, $2 \mathrm{mM}$ of $\mathrm{MgCl}_{2}, 1 \mathrm{U}$ of Go-taq polymerase, $0.5 \mu \mathrm{M}$ of each primers and, approximately, $1.5 \mu \mathrm{L}$ of DNA in a final volume of $25 \mu \mathrm{L}$. The amplification conditions used were specified by Honda et al. [18] as follows: initial denaturation at $95{ }^{\circ} \mathrm{C}$ for $5 \mathrm{~min}$, followed by 35 amplification cycles. Each cycle consisted of denaturation at $95^{\circ} \mathrm{C}$ for $30 \mathrm{~s}$, alignment for $30 \mathrm{~s}$ at $55^{\circ} \mathrm{C}$ and extension at $72{ }^{\circ} \mathrm{C}$ for $1 \mathrm{~min}$, with a final extension step of $72{ }^{\circ} \mathrm{C}$ for $10 \mathrm{~min}$. PCR products were visualized through $2 \%$ in agarose 
gel electrophoresis. The bands were visualized by gel staining with ethidium bromide $\left(0.5 \mu \mathrm{g} \mathrm{mL}^{-1}\right)$ and exposure with a UV transilluminator.

Bands of expected sizes ( $>1500 \mathrm{pb}$ ) were purified using the E.Z.N.A ${ }^{\circledR}$ Gel Purification Kit, following the supplier's instructions. The purified PCR product was ligated to the pGEM $^{\circledR}$ T-Easy vector (Promega) using a vector ratio of 3:1 in a final reaction volume of $10 \mu \mathrm{L}$ and then incubated overnight at $4{ }^{\circ} \mathrm{C}$.

Bacterial transformation was done with a vial of competent Escherichia coli cells (JM109 ${ }^{\circledR}$ Promega) and the ligation product (recombinant plasmid), following the thermal shock methodology. The transformed bacteria were seeded in Petri dishes with LB agar and ampicillin $\left(50 \mu \mathrm{g} \mathrm{mL}^{-1}\right)$, IPTG $(0.5 \mathrm{mM})$ and $\beta$-galactosidase $\left(50 \mathrm{mg} \mathrm{mL}^{-1}\right)$, which allowed for identifying the bacteria in the recombinant plasmid. The seeded plates were left to grow overnight at $37^{\circ} \mathrm{C}$. The positive clones were confirmed by conventional PCR in the colonies, and the bands were viewed by SafeView ${ }^{\mathrm{TM}}$ staining with and exposure in a UV transilluminator. The positive colonies were grown in liquid LB medium with ampicillin $\left(50 \mu \mathrm{g} \mathrm{mL}^{-1}\right)$, and the DNA plasmid was purified with the commercial kit commercial Plasmid Miniprep kit II E.Z.N.A. ${ }^{\circledR}$, following the supplier's instructions.

Purified plasmids containing the cloned segment were sequenced by MACROGEN (South Korea). To identify the microorganisms, the sequences obtained were compared with the sequences available at the GenBank Database by the BLAST program available at the NCBI website. The phylogenetic tree based on the ribosomal gene $18 \mathrm{~s}$ rRNA sequence was processed with the MEGA 6 and Geneious version 6.0.3 programs (Biomatters, Ltd.)

The sequences obtained from the studied strains were entered into the GenBank database with the following access numbers: KJ530974 (C6), KJ530975 (16CC1B), KJ530976 (NCYC 4007), KJ530977 (C3), KJ530978 (C30), KJ530979 (C46), KJ530980 (C51), KJ530981 (C24), KJ530982 (P39) and KJ530983 (C4).

\subsection{Inoculum Production of NCYC 4007 and NCYC 1146}

Two strains of marine yeast, NCYC 4007 and NCYC 1146, were used. Both strains isolated from the marine ecosystem of Chile (NCYC 4007 former C36 in [9]) were stored in the National Collection of Yeast Cultures (NCYC) in the United Kingdom under the Budapest Treaty. Strains were activated through the development of $100 \mathrm{~mL}$ of inoculum under Sabouraud growth medium at $21^{\circ} \mathrm{C}$ for 7 days. Then, 500 -mL flasks were used to cultivate an inoculum $\left(10^{6}\right.$ cell $\left.\mathrm{mL}^{-1}\right)$ for subsequent use in the evaluation of the growth media.

\subsection{Raw Glycerol as a Carbon Source}

In the present study, we evaluated as a carbon source: (1) raw glycerol originating from the biodiesel industry (RG), (2) analytical Grade glycerol (AG) and (3) glucose from commercial Sabouraud culture medium (SM). The RGM and AGM media were formulated with a $10 \%(v / v)$ of raw glycerol (nominal concentration) and $10 \%(v / v)$ of analytical grade of glycerol, respectively. Additionally, both mediums contained $7 \mathrm{~g} \mathrm{~L}^{-1}$ of peptone, $7 \mathrm{~g} \mathrm{~L}^{-1}$ of yeast extract, and $30 \mathrm{U} \mathrm{mL}^{-1}$ of penicillin-streptomycin. All media were performed with seawater (salinity $=35$ ), filtered to $0.22 \mu \mathrm{m}$ and autoclaved at $121^{\circ} \mathrm{C}$ for $15 \mathrm{~min}$. With the aim of selecting the best growth medium, these media were assessed at three temperatures $\left(15,21\right.$ and $31{ }^{\circ} \mathrm{C}$ ), and the production of the biomass, DHA or carotenoids (NCYC 4007 and NCYC 1146, respectively) in a bioreactor (10 L) was evaluated.

In this study, the raw glycerol used corresponded to a highly concentrate fraction of glycerol collected during the industrial production of biodiesel from fried food waste oils (Comercial Verdemar Ltd. Company, COVEMAR-CHILE) (Talcahuano, Chile).

\subsection{Production of Docosahexaenoic Acid (DHA) and Total Carotenoids (TC)}

Aliquots taken every $24 \mathrm{~h}$ from the bioprocesses mentioned above were used to determine the amount of DHA and TC. Determination of DHA was carried out in three stages: (1) saponification extraction, (2) solvent changes and (3) chromatographic analysis, 
according to [20]. The saponification reaction was performed using $100 \mathrm{mg}$ of wet biomass adding $1 \mathrm{~mL}$ of $\mathrm{NaOH}$ at $0.5 \mathrm{M}$ in $96 \%$ ethanol. The cellular rupture was performed using an Ultra Turrax for $1 \mathrm{~min}$. After this, it was centrifuged at $7000 \mathrm{rpm}$ for $5 \mathrm{~min}$, which dismissed any solid residue. One milliliter of $\mathrm{HC} 1$ was added to the obtained supernatant at $0.6 \mathrm{~N}$ and $3 \mathrm{~mL}$ of ethyl acetate placed in a vortex mixer for $1 \mathrm{~min}$. The samples were incubated for $30 \mathrm{~min}$ at room temperature; to obtain phase separation, the upper phase was dried with $\mathrm{N}_{2}(\mathrm{~g})$ at room temperature. After this, the phases were freeze-dried to eliminate water residue. The freeze-dried samples were diluted in $400 \mu \mathrm{L}$ of filtered methanol with polyethersulfone membranes RF-Jet Syringe Filter of $13 \mathrm{~mm}$, with $0.45-\mu \mathrm{m}$ pores and, after this, they were stored at $-20^{\circ} \mathrm{C}$ for analysis. For chromatographic analysis, a HPLC VWR ${ }^{\text {TM }}$ HITACHI was used, a column LC- 18 Supelco ${ }^{\circledR}$ of $15 \mathrm{~cm} \times 4.6 \mathrm{~mm}$. The mobile phase was performed at a gradient of $100 \%$ of A $\left(75 \%\right.$ of ACN LiChrosolv $\left.{ }^{\circledR}\right)$ with a flow of $1 \mathrm{~mL} \mathrm{~min}^{-1}$ at $50 \%$ of B (pure ACN LiChrosolv ${ }^{\circledR}$ ) with a flow of $2 \mathrm{~mL} \mathrm{~min}^{-1}$ over $15 \mathrm{~min}$; consecutively, the flow changed to $1 \mathrm{~mL} \mathrm{~min}^{-1}$ until the 30-min cycle finished. Both A and B solutions were acidified with $0.12 \%$ of acetic acid (Sigma-Aldrich ${ }^{\circledR}$, St. Louis, MO, USA). The detection was performed at $195 \mathrm{~nm}$ with an injection volume of $10 \mu \mathrm{L}$ per sample. The DHA concentration was determined by a calibration curve performed using standard docosahexaenoic acid (Sigma-Aldrich ${ }^{\circledR}$ ).

The determination of total carotenoids (TC) was performed by a methodology outlined by Rodher [20]. For this, $50 \mathrm{mg}$ of wet biomass were weighed, obtained from aliquots during the bioprocesses. Once the samples were incubated and were centrifuged at 11,000 rpm for $10 \mathrm{~min}$, the reached supernatant was transferred to a new tube for a further spectrophotometric analysis. Prior to the analysis, a potassium dichromate calibration curve was built of a stock solution of $3.6 \mathrm{mg} \mathrm{mL}^{-1}$. Both the dilutions used to build the calibration curve and the samples were measured at $560 \mathrm{~nm}$ in glass cells. The TC concentration was determined, considering that $0.036 \%$ of potassium dichromate was equivalent to $2.6 \mathrm{ng} \mathrm{mL}^{-1}$ of TC.

\subsection{Kinetic Growth and Biomass Production}

The description of kinetic growth from the cultured strains was determined through a cell count every $12 \mathrm{~h}$ by a Neubauer Improved chamber. The obtained data were used to determine the kinetic parameters: maximum growth speed ( $\mu$ maximum) and duplication time (Td). The total biomass produced was quantified at the end of each bioprocess, collected in 50-mL tubes, by spinning at $3600 \mathrm{rpm}$ for $30 \mathrm{~min}$ and washed twice in distilled water. Following this, the biomass was freeze-dried and quantified in dry weight.

The quantification in dry weight was performed by two methods: (1) the quantification of the biomass being oven-dried at $100{ }^{\circ} \mathrm{C}$ (oven-dried weight; ODW) and (2) quantification of the biomass by lyophilization (freeze-dried weight; FDW). In the case of the evaluation of the biomass obtained from the culture media, the percentages of DHA and TC were expressed as ODW. For the profiles of fatty acids and carotenoids, the biomass obtained corresponded to the FDW.

\subsection{Fatty Acid Profiles}

The extraction of lipids from the lyophilized cultures of Rhodotorula sp. NCYC 4007 was carried out according to a modified Bligh and Dyer [20], a procedure that substituted dichloromethane for chloroform. Samples (ca. $20 \mathrm{mg}$ ) were sequentially extracted by ultra-sonication with 30-mL dichloromethane/methanol (1:3 v/v, 2X, 1:1 v/v, 1X and dichloromethane $(2 \mathrm{X})$ ). The lipid extract was concentrated with a rotary evaporator and dried with anhydrous $\mathrm{Na}_{2} \mathrm{SO}_{4}$.

Extracts were saponified with $15 \mathrm{~mL}$ of $0.5-\mathrm{N} \mathrm{KOH}: \mathrm{MeOH}$ [20], and the non-saponifi able lipids were separated with hexane. The remaining aqueous extracts were acidified with 6-N HCl, and the fatty acids were extracted with hexane. The solvent was reduced by rotary evaporation, and the fatty acids were converted into methyl esters (FAMEs) with $1-\mathrm{mL} 10 \% \mathrm{BF} 3 / \mathrm{MeOH}$ for $1 \mathrm{~h}$ at $70{ }^{\circ} \mathrm{C}$ [21,22], $1 \mathrm{~mL}$ of milli-Q water was added 
and FAMEs was extracted with hexane. The organic fraction was then dried under a stream of $\mathrm{N}_{2}$. Samples were injected into a gas chromatograph (Agilent 6890 GC series) coupled to a mass spectrometer detector (Agilent 5972 MS series) equipped with a HP5-MS column (30 m × $1600.25 \mathrm{~mm}, 0.25-\mu \mathrm{m}$ film thickness: Agilent Technologies) using He as a carrier gas. The oven temperature was $120^{\circ} \mathrm{C}(2 \mathrm{~min})$ to $290{ }^{\circ} \mathrm{C}$ at $4{ }^{\circ} \mathrm{C} \mathrm{min}-1$, held for $5 \mathrm{~min}$. The detector was operated in electron impact mode $(70 \mathrm{eV})$ with an ion source at $230{ }^{\circ} \mathrm{C}$. Mass spectra was acquired in full-scan mode $(\mathrm{m} / \mathrm{z}$ range $40-600$, scan rate $2.6 \mathrm{~s}^{-1}$ ), and FAMEs were assigned using the retention times of a standard mixture (FAME mix, Supelco Analytical), the internal library of the mass spectrometer and the electronic data base available at website GoDaddy for details (GoDaddy, LLC). Quantification was carried out using a calibration curve with serial dilution of the FAME standard mix. The coefficient of variation for the analytical method was $14 \%$, routinely measured with five replicate analyses.

\subsection{Carotenoids Profiles}

Biomass of the marine yeast strain NCYC 1146 was lyophilized and was used to determine the carotenoid profiles. For this, $1 \mathrm{~g}$ of freeze-dried biomass was weighed, and pigment extraction was performed with $50 \mathrm{~mL}$ of acetone. Extracts were centrifuged at $2000 \mathrm{rpm}$ for $20 \mathrm{~min}$, and $2 \mathrm{~mL}$ of acetone was added and centrifuged for $20 \mathrm{~min}$. To dissolve oil droplets formed in the extracts (to avoid interference during reading), $1 \mathrm{~mL}$ of acetone was added to the supernatant. The samples were quantified in a HPLC Hitachi L6200, with a column RP-18 Supelco of $12.5-\mathrm{cm}$-diameter and $5-\mu \mathrm{m}$-sized particles. A mobile phase gradient system of water/ethyl acetate/methanol was used. A ratio of 2:10:88 (v/v/v)

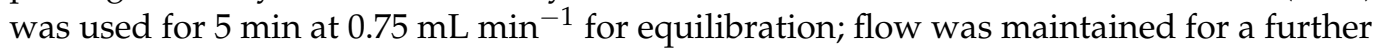
$10 \mathrm{~min}$. Between 10 and $30 \mathrm{~min}$, the solvent ratio was ramped to 2:50:48, and the flow rate was adjusted to $1.5 \mathrm{~mL} \mathrm{~min}^{-1}$. A six-carotenoid standard, comprised of beta-carotene, canthaxanthin, astaxanthin, adonirrubin, zeaxanthin and 3-hidroxy echinenone, was used for identification purposes. These standard carotenoids were chosen, as they constitute the main starting, intermediate and final products within the microbial carotenoid pathway and have perceived commercial values.

\subsection{Determination of Glucose, Phosphorus, Cholesterol and Live Microbial Biomass (ATP)}

Aliquots of $1 \mathrm{~mL}$ were taken from the bioprocesses tested every $24 \mathrm{~h}$ for the subsequent glucose (intracellular and the culture media), phosphorus, cholesterol and live microbial biomass quantifications (ATP). The identification of glucose, phosphorus and intracellular cholesterol was performed through an extraction with phosphate buffer at $200 \mathrm{mM}$ in ratio of 1:10 (p/v), homogenized with an Ultra Turrax for $1 \mathrm{~min}$ and centrifuged at $3000 \mathrm{rpm}$ for $5 \mathrm{~min}$. The supernatant obtained was utilized for the quantification. In the case of quantification phosphorus, it was determined the concentration of the buffer phosphate, and this value was used to normalize the samples. In the case of identifying glucose present in the culture liquid media, the samples were directly analyzed from the aliquots without prior treatment.

The quantification of glucose, phosphorus and cholesterol were performed using commercial kits by the company Human Diagnostics (Wiesbaden, Germany), following the supplier's instructions (Glucose liquicolor by the Glucose Oxidase (GOD)-Peroxidase (POD) method at $500 \mathrm{~nm}$, Phosphorus liquirapid by phosphomolybdic acid at $340 \mathrm{~nm}$ and Cholesterol liquicolor by Cholesterol Oxidase (CHOD)-Peroxidase 4 Amino antipyrine (PAP) method at $500 \mathrm{~nm}$ ).

To determine the fraction of ATP present in the aliquots, two steps were carried out according to the methodology described by Holm-Hansen and Booth [23]. The first one consisted of an ATP extraction through a boiling bath with organic buffer (Tris $20 \mathrm{mM}$, $\mathrm{pH}$ 7.7), and the second step, consistent with the ATP quantification extracted during the testing of bioluminescence for which an ATP meter, utilized Turner Designs Model TD $20 / 20$. In addition, a calibration curve was performed between $0.39 \mathrm{nM}$ and $100 \mathrm{nM}$ from a 
stock solution of $1 \mathrm{M}$ of ATP; through serial dilutions and to quantify the extracted ATP, FLE-250 was used to generate the complex enzyme substrate.

\subsection{Enzymatic Activity of Malate Dehydrogenase (MDH) and Lactate Dehydrogenase (LDH)}

The determination of enzymatic activity of MDH and LDH from the strains, aliquots $(1 \mathrm{~mL})$ were taken every $24 \mathrm{~h}$ and centrifuged at $11,000 \mathrm{rpm}$ for $1 \mathrm{~min}$. The supernatant obtained was extracted in a phosphate buffer $200 \mathrm{mM}$ with an Ultra Turrax for $30 \mathrm{~s}$ and then centrifuged at $3000 \mathrm{rpm}$ for $5 \mathrm{~min}$. The enzymatic activities were quantified from the supernatants following the method described by González and Quiñones [24], and the enzymatic activities are shown in nmol of Nicotinamide Adenine Dinucleotide (NADHreduced form) $\mathrm{min}^{-1} \mathrm{~mL}^{-1}$. The activity of L-malate dehydrogenase was assayed, as it catalyzed the formation of malate from oxaloacetate. The assay medium contained 80-mM K${ }_{2} \mathrm{HPO}_{4}$ buffer, $\mathrm{pH} 7.9$, at $20{ }^{\circ} \mathrm{C}, 0.1-\mathrm{mM} \mathrm{NADH}, 150-\mathrm{mM} \mathrm{MgCl}_{2} * 6 \mathrm{H}_{2} \mathrm{O}$ and $0.2-\mathrm{mM}$ oxaloacetate. Absorption was monitored at $340 \mathrm{~nm}$ following the addition of the supernatant. Activity of $\mathrm{LDH}$ was measured with a reaction mixture that contained $80-\mathrm{mM}$ $\mathrm{K}_{2} \mathrm{HPO}_{4}$ buffer, $\mathrm{pH} 7.9$, at $20{ }^{\circ} \mathrm{C}, 3.2-\mathrm{mM}$ pyruvate and 0.1-mM NADH. Absorbance was monitored at $340 \mathrm{~nm}$ following the addition of the supernatant. MDH and LDH activity measurements were corrected for nonspecific NADH oxidation.

\subsection{Data Analysis}

Statistical analysis was carried out on the results obtained from each of the tested cultures with the strains NCYC 4007 and NCYC 1146. In the first step, the homogeneity of variance (Bartlett, London, UK) and normality of data (Kolmogorov-Smirnov test) were analyzed. Consequently, the significance between DHA productivity, TC and total biomass was determined by one-way variance analysis (ANOVA). Furthermore, the analyses determined if significant correlations existed between the cell counts, enzymatic activities of $\mathrm{MDH}, \mathrm{LDH}$ and live microbial biomass. All these analyses were carried out using the statistic software R Studio 3.3.1 (R. RStudio, PBC, Boston, MA, USA).

\section{Results}

\subsection{Molecular Genotyping of Marine Yeast NCYC1146 Strain}

The results obtained show that the amplification of the ribosome gene 18s rRNA from the NCYC 1146 strain generates a fragment of $1500 \mathrm{pb}$ (data not shown). The analyses carried out by BLAST show that this strain shares a $97 \%$ similarity to species within the genus Rhodotorula. The strain is more distant to the species from genus Rhodosporidium and Thraustochytrium (91\% and $81 \%$, respectively). The phylogenetic tree shows the presence of two large clusters, one of which consisted of marine fungoid species, the producers of carotenoid pigments described by Pino et al. [9]. Another one was formed of NCYC4007, NCYC1146 strain and species from the genus Rhodotorula and Rhodosporidium (Figure 1).

\subsection{Biomass Production and Optimum Growth Temperature of the Marine Rhodotorula sp. NCYC4007 and NCYC1146}

Using raw and analytical grade glycerol, as well as glucose, as main source of carbon in a bioreactor of $10 \mathrm{~L}$, the performance of the total produced biomass (\% of FDW) at the end of the bioprocess $\left(240 \mathrm{~h}\right.$ ) fluctuated between 54 and $152 \mathrm{~g} \mathrm{~L}^{-1}$ for the NCYC 4007 strain and between 49 and $192 \mathrm{~g} \mathrm{~L}^{-1}$ for NCYC1146 (Table 1). Nonetheless, the production of the biomass obtained from the culture of RGM at $15^{\circ} \mathrm{C}$ is significantly higher $(p<0.05)$ for the NCYC4007 strain and that of NCYC1146 (Table 1). Consistently, the identified growth parameters described that the maximum growth speed ( $\mu$ maximum) and the duplication time (Td) were also higher than the RGM at $15^{\circ} \mathrm{C}$ for both strains (Table 1). Due to this, raw glycerol medium produces a significantly higher biomass in less time than other tested culture media at $15^{\circ} \mathrm{C}(p<0.05$; Table 1$)$, and there are no inhibitory effects on the growth. 


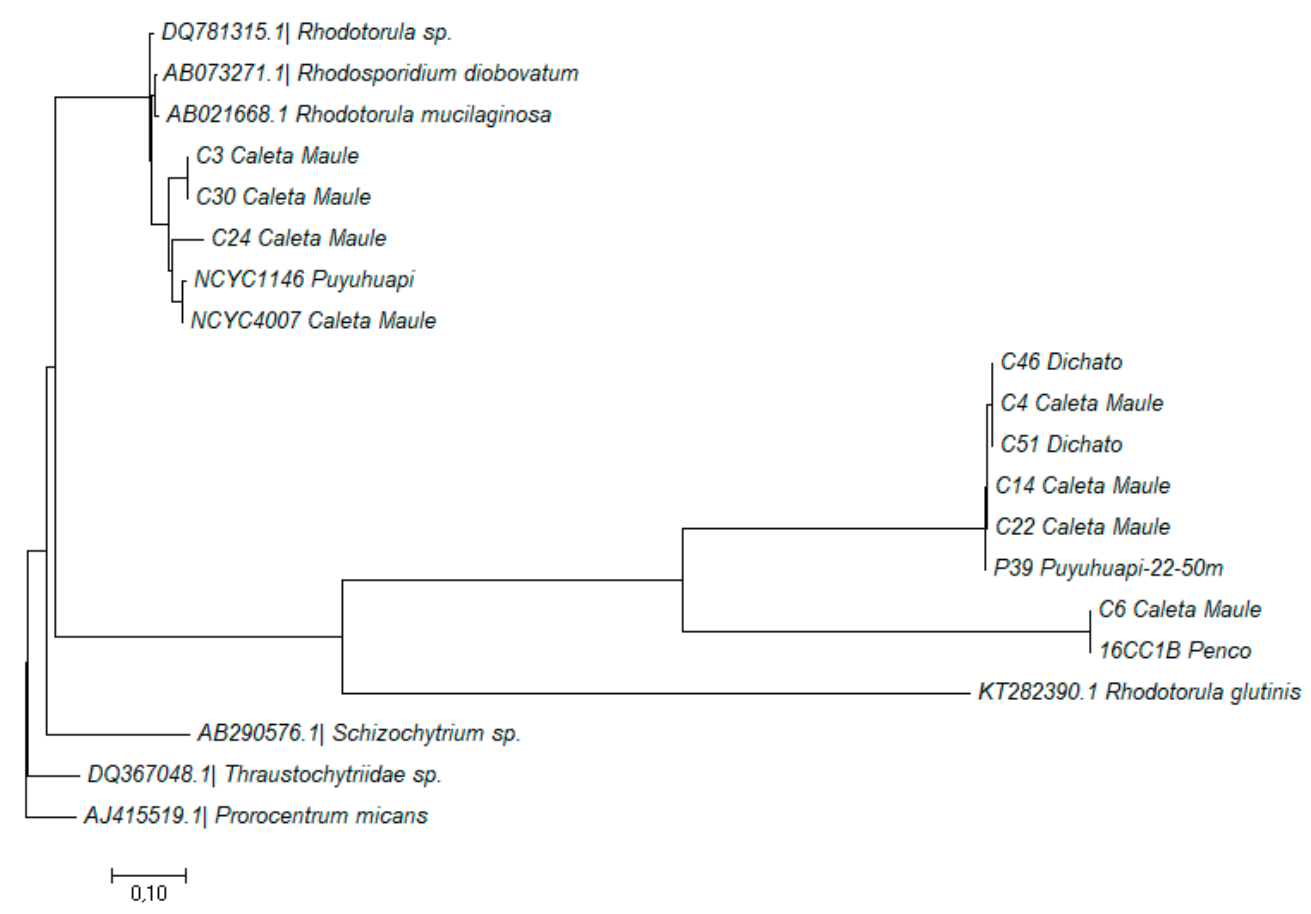

Figure 1. Location the NCYC1146 strain on the phylogenetic tree, based on the ribosomal gene 18s rRNA sequence, compared to the marine fungoides sequences described by Pino et al. [9]. To carry out the comparison, the species Rhodotorula sp., Rhodotorula mucilaginosa, Rhodotorula glutinis, Rhodosporidium diobovatum, Schizochytrium sp. and Thraustochytriidae sp. were used as representatives for the genus Rhodotorula, Rhodosporidium, Schizochytrium and Thraustochytrium. Prorocentrum micans was used as an outgroup. The tree was constructed by the Neighbor-joining (NJ) method and the MEGA 6 program.

Table 1. Kinetic growth parameters of the NCYC 4007 and NCYC 1146 strains obtained by the tested culture media at three different temperatures $\left(15,21\right.$ and $\left.31^{\circ} \mathrm{C}\right)$. Total biomass production in dry weight (B), maximum growth speed ( $\mu$ maximum) and duplication time (Td).

\begin{tabular}{ccccccc}
\hline \multirow{2}{*}{$\begin{array}{c}\text { Culture } \\
\text { Media }\end{array}$} & \multicolumn{2}{c}{ B (g) } & \multicolumn{2}{c}{$\mu$ Maximum $\left(\mathbf{h}^{-\mathbf{1}}\right)$} & \multicolumn{2}{c}{ Td (h) } \\
\cline { 2 - 7 } & NCYC4007 & NCYC1146 & NCYC4007 & NCYC1146 & NCYC4007 & NCYC1146 \\
\hline SM $\left(15^{\circ} \mathrm{C}\right)$ & 108 & 97.2 & 0.03 & 0.05 & 23 & 14 \\
SM $\left(21^{\circ} \mathrm{C}\right)$ & 102 & 91.8 & 0.03 & 0.04 & 23 & 17 \\
SM $\left(31^{\circ} \mathrm{C}\right)$ & 96 & 86.4 & 0.03 & 0.04 & 23 & 17 \\
AGM $\left(15^{\circ} \mathrm{C}\right)$ & 126 & 113.4 & 0.03 & 0.05 & 23 & 14 \\
AGM $\left(21^{\circ} \mathrm{C}\right)$ & 116 & 104.4 & 0.03 & 0.04 & 23 & 17 \\
AGM $\left(31^{\circ} \mathrm{C}\right)$ & 126 & 113.4 & 0.05 & 0.07 & 14 & 10 \\
RGM $\left(15^{\circ} \mathrm{C}\right)$ & ${ }^{*} 152$ & $* 191.8$ & $* 0.08$ & ${ }^{*} 0.11$ & $* 9$ & $* 6$ \\
RGM $\left(21^{\circ} \mathrm{C}\right)$ & 92 & 82.8 & 0.04 & 0.06 & 17 & 12 \\
RGM $\left(31^{\circ} \mathrm{C}\right)$ & 54 & 48.6 & 0.05 & 0.07 & 14 & 10 \\
\hline
\end{tabular}

* Significant statics value $(<0.05)$.

\subsection{DHA Production and Fatty Acid Profiles of NCYC4007 Strain}

In raw and analytical grade glycerol, as well as glucose, the Rhodotorula strain NCYC 4007 presents a DHA production between 19\% and 23\% in ODW (Figure 2a-c). Comparing these three carbon sources, raw glycerol allowed the maximum DHA production at $144 \mathrm{~h}$ of cultivation, with a lesser time registered with analytical glycerol and glucose (192 and $216 \mathrm{~h}$, respectively; Figure $2 \mathrm{a}, \mathrm{b}$ ). The results also indicated, at $15^{\circ} \mathrm{C}$, a significantly higher production of DHA $(23 \%$ ODW; $p<0.05)$ when NCYC4007 was cultivated in raw glycerol (Figure 2c) compared to analytical grade glycerol and glucose was obtained. Thus, the DHA production in this strain is consistent from what was observed with respect to the biomass production in all carbon sources tested (Table 1). Given that this strain showed the greatest total DHA production (ODW) at $15^{\circ} \mathrm{C}$ with the three carbon sources used, this was set as the optimum temperature to cultivate and acquire the fatty acid profiles of NCYC 
4007 (Table 2). In general terms, the three carbon sources tested showed similar results for this strain, with a greater percentage of unsaturated fatty acids (UFAs) than saturated (SFAs). The high percentage of UFAs was achieved using glucose, followed by AG and RG (Table 2). The fatty acid profiles also showed that the NCYC 4007 strain produces a greater DHA percentage in respect to TFA using glucose (27\% of TFA) than in the AG, albeit the DHA concentration ( $\mathrm{mg} \mathrm{g}^{-1}$ FDW biomass) obtained with glucose presented no significant differences with RG (Table 2).

\subsection{Production of Total Carotenoids and Carotenoid Pigment Profiles of NCYC1146 Strain}

For each of the three carbon sources used at the three tested temperatures, the TC production in the strain varied between $10 \%$ and $19 \%$ of the dry biomass (ODW; Figure 2d-f), and between 192 and $216 \mathrm{~h}$, the maximum production was presented. With respect to the three tested media, the NCYC1146 strain presents a significantly greater production $(p<0.05)$ of TC with RG at $15^{\circ} \mathrm{C}(19 \%$ ODW $)$, like what was observed when this carbon source was used for DHA production with the NCYC4007 strain. The NCYC1146 strain produced the maximum total of TC at $192 \mathrm{~h}$ of cultivation (Figure 2f) in less time registered when glucose and AG was used (216 h; Figure 2d,e).

In the carotenoid profile derived from the biomass produced from the NCYC1146 strain, the presence of four pigments was observed (Figure 3). On average, the greatest quantity of substances produced were $\beta$-carotene $\left(86.4 \pm 20.5 \mu \mathrm{g} \mathrm{g}^{-1} \mathrm{FDW}\right)$, followed by adonirrubin $\left(48.8 \pm 8.7 \mu \mathrm{g} \mathrm{g}^{-1}\right.$ FDW $)$, 3-hydroxyechinenone $\left(44.2 \pm 23.2 \mu \mathrm{g} \mathrm{g}^{-1} \mathrm{FDW}\right)$ and canthaxanthin $\left(24.8 \pm 21.6 \mu \mathrm{g} \mathrm{g}^{-1}\right.$ FDW). With glycerol (AG \& RG), canthaxanthin a non-synthesized substance when glucose was produced. The concentration of this substance acquired from the final culture using both raw and analytical glycerol presented no significant differences (Figure 3).
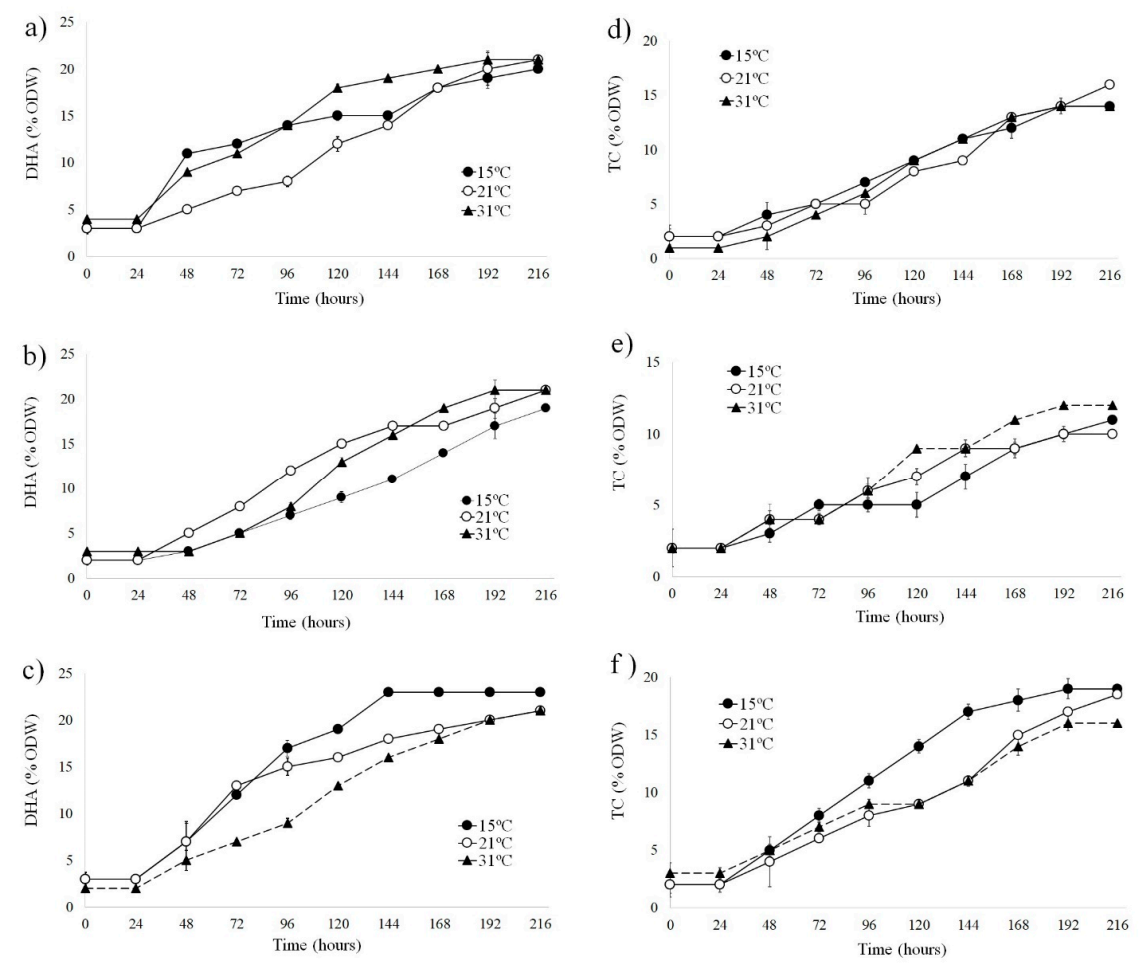

Figure 2. Average productions $\pm \mathrm{SD}$ docosahexaenoic acid (DHA) and total carotenoids (TC) of the NCYC4007 and NCYC1146 strains. (a-c). Culture from the NCYC4007 strain in bioprocesses with SM, AGM and RGM media, respectively. (d-f). Culture from the NCYC1146 strain in bioprocesses with SM, AGM and RGM media, respectively. The production of these substances is shown in percentages, in respect to the biomass in oven-dried weight (ODW). 
Table 2. Fatty acids profile from the NCYC 4007 strain cultivated in three different culture media at $15{ }^{\circ} \mathrm{C}$ : Sabouraud medium (SM), media formulated with analytic grade glycerol (AGM) and raw glycerol (RGM). The results are shown as the percentage of total fatty acid (TFA). In addition, the amount of fatty acids (FA) and DHA are showed in $\mathrm{mg} \mathrm{g}^{-1}$ freeze-dried weight (FDW) biomass.

\begin{tabular}{cccc}
\hline Carbon Source & SM & AGM & RGM \\
\hline Fatty Acids & & (\%) TFA & \\
\hline C14:0 & 0.2 & 0.2 & 0.8 \\
C15:0 & 0.2 & 0.2 & 0.6 \\
C16:0 & 3.8 & 4.5 & 8.9 \\
C17:0 & 0.6 & 0.5 & 1.1 \\
C18:0 & 0.0 & 4.7 & 10.5 \\
C20:0 & 0.1 & 0.1 & 0.3 \\
C22:0 & 0.2 & 0.2 & 0.5 \\
C23:0 & 0.0 & 0.0 & 0.2 \\
C24:0 & 0.6 & 0.5 & 1.0 \\
C25:0 & 0.0 & 0.0 & 0.2 \\
C26:0 & 0.0 & 0.0 & 0.1 \\
C16:1 $(\omega 9)$ & 1.5 & 0.7 & 1.2 \\
C17:1 $(\omega 7)$ & 1.0 & 0.3 & 0.7 \\
C18:1 $(\omega 9)$ & 53.0 & 55.4 & 0.0 \\
C18:2 $(\omega 6)$ & 4.6 & 3.0 & 42.2 \\
C20:1 $(\omega 9)$ & 0.1 & 0.1 & 0.2 \\
C20:5 $(\omega 3)$ & 7.2 & 10.2 & 9.2 \\
C22:6 ( $\omega 3)$ & 27.0 & 19.2 & 22.3 \\
\hline Total \% SFA & 5.6 & 11.2 & 24.1 \\
Total \% PUFA & 94.4 & 88.9 & 75.8 \\
\hline Total FA $\left(\mathrm{mg} \mathrm{g}^{-1}\right)$ & 46.2 & 45.3 & 53.6 \\
Total DHA $\left(\mathrm{mg} \mathrm{g}^{-1}\right)$ & 12.5 & 6.8 & 11.9 \\
\hline
\end{tabular}

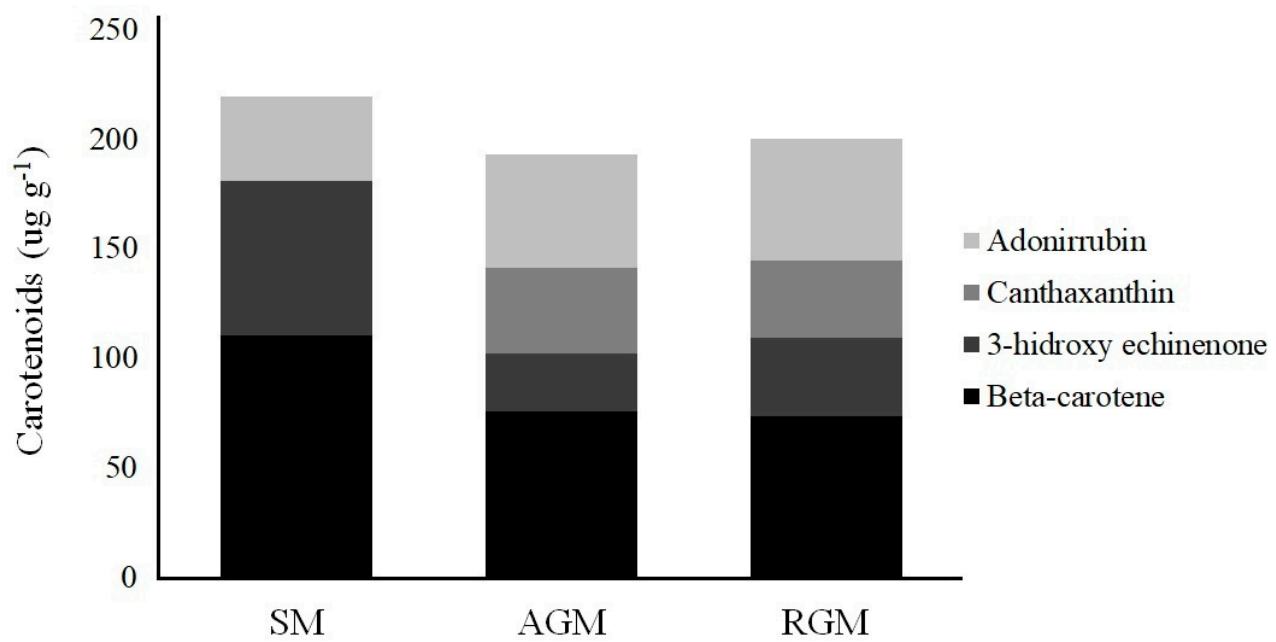

Figure 3. Carotenoid pigment profile of the NCYC1146 strain acquired from the total biomass produced from each of the bioprocesses carried out in the culture media SM, AGM and RGM at $15{ }^{\circ} \mathrm{C}$. The results are shown in $\mu \mathrm{g} \mathrm{g}^{-1}$.

\subsection{Metabolic Parameters of the Strains in Cultivated in Raw Glycerol}

Using raw glycerol, the NCYC4007 strain at $15{ }^{\circ} \mathrm{C}$ presents a maximum production of DHA (23\% DHA in ODW) at $144 \mathrm{~h}$ of cultivation and could maintain this production for four days (Figure 4a). A similar situation was observed for the NCYC1146 strain but with respect to carotenoid production (Figure $4 \mathrm{~b}$ ). For each strain, the live microbial biomass (ATP) was kept at basal levels until the culture reached the maximum DHA or TC 
production; from here on, an increase of ATP was observed and, subsequently, an increase in the cell count, which reached the maximum at 216 and $240 \mathrm{~h}$ for the NCYC4007 and NCYC1146 strains, respectively. (Figure 4a,b). In addition, observations were made at $24 \mathrm{~h}$ when the culture began the synthesis of carotenoids in the NCYC4007 strain, reaching values of $15 \%$ of CT in ODW at the end of the culture (Figure 4a). The intracellular glucose concentration determined in both strains presented a decrease in the time, contrary to what was observed in the culture medium, where an accumulation was observed during the cultivation (Figure 4c,d).

a)
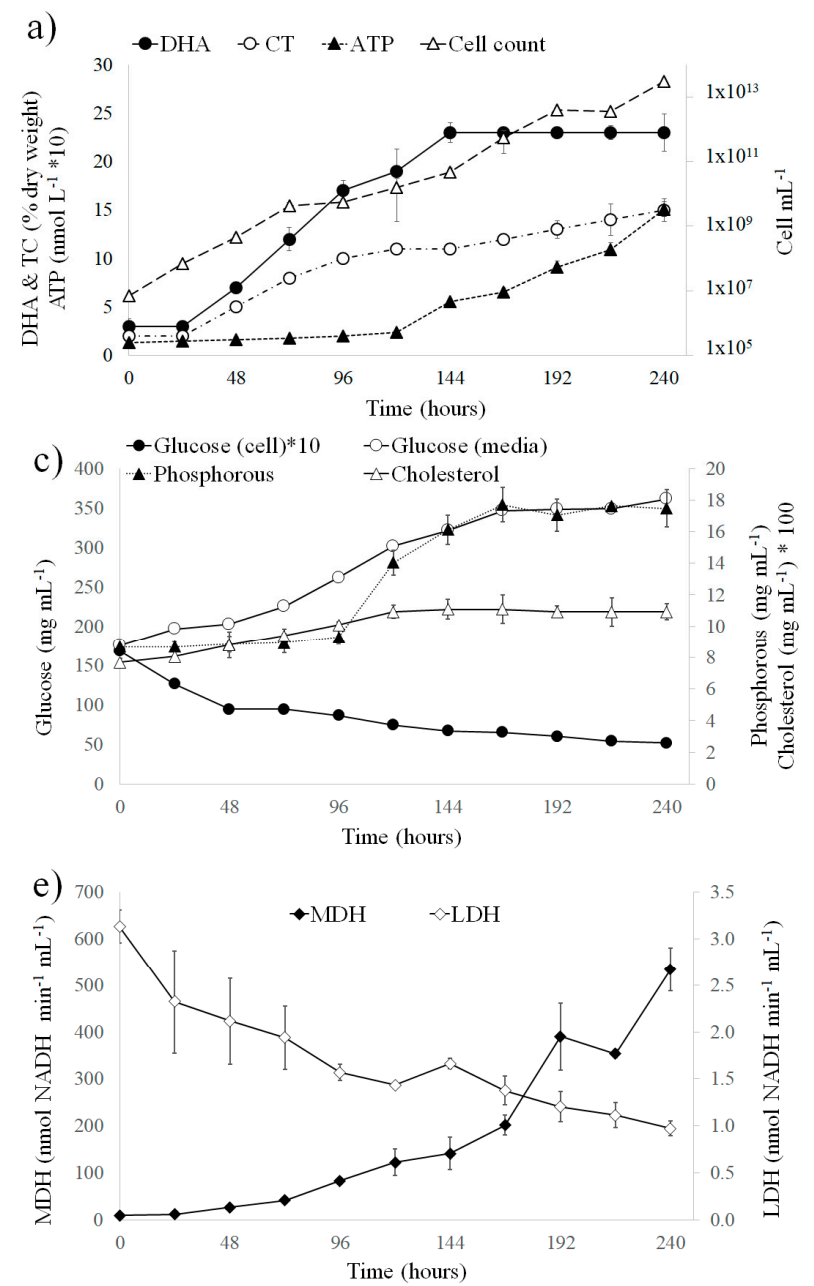

b)

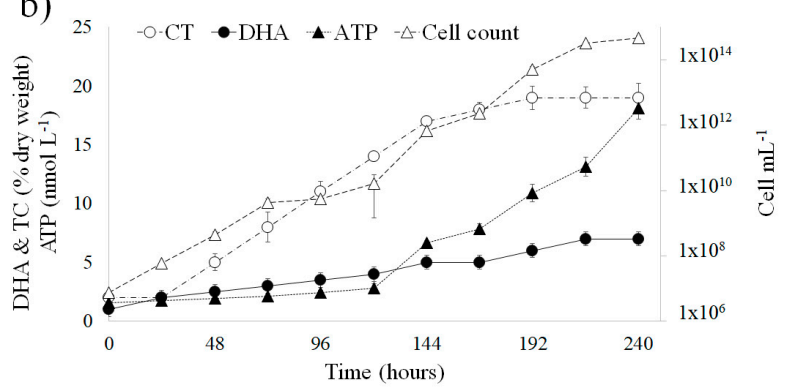

d)

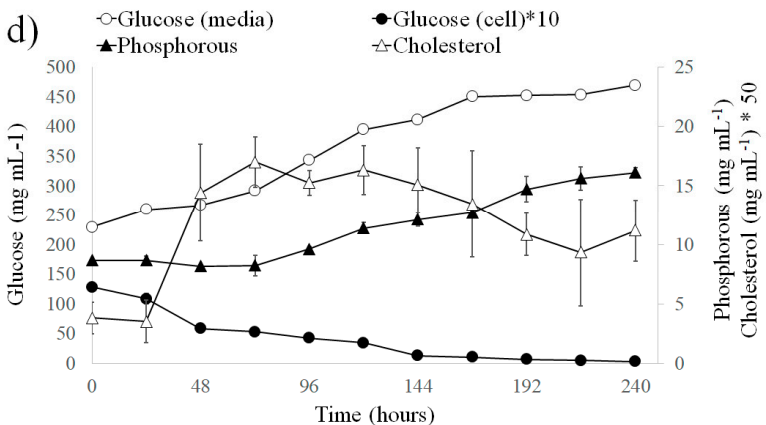

f)

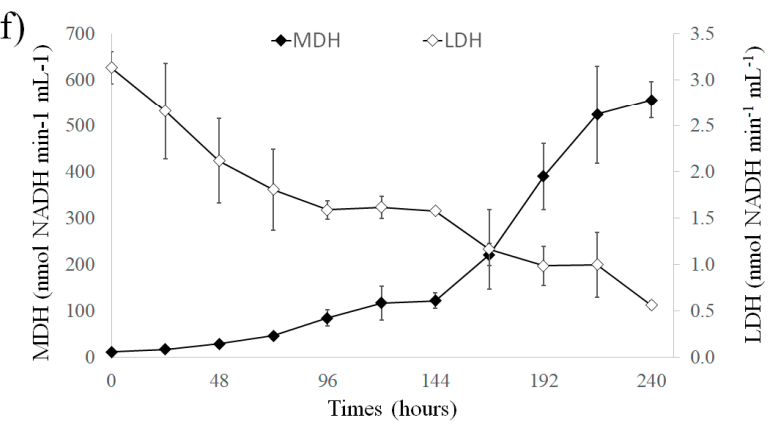

Figure 4. Average production \pm SD of metabolic parameters determined for the NCYC4007 and NCYC1146 strains, cultivated in RGM at $15{ }^{\circ} \mathrm{C} .(\mathbf{a}, \mathbf{b})$ Docosahexaenoic acid production (DHA), total carotenoids (TC), live microbial biomass (ATP) and cell count of strains NCYC4007 and NCYC1146, respectively. (c,d) Intracellular glucose concentration and in the culture media, total phosphorus and intracellular cholesterol of strains NCYC4007 and NCYC1146, respectively. (e,f) Enzymatic activities of MDH and LDH of the strains NCYC4007 and NCYC1146, respectively.

\section{Discussion}

The phylogenetic analysis of the ribosome gene 18s rRNA from the NCYC1146 strain was made with a fragment of similar size to that described by Honda et al. [19]. The NCYC1146 strain could be considered as a species of marine Rhodotorula sp., owing to the genetic similarity with the NCYC4007 strain (Figure 1) described by Pino et al. [9]. Despite the genetic similarity between NCYC4007 and NCYC1146, both strains can produce different substances that can be associated with the functional variability of the microorganisms when confronted by different environmental conditions. In this case, NCYC4007 comes from a temperate ecosystem with strong winds during upwelling periods [25], while 
NCYC1146 is significantly different, isolated in a cold ecosystem with a high level of fresh water associated with adjacent rivers coming from the melting of snowdrifts and the high level of lignocellulosic material from a forestry origin [26].

This is the first report of marine Rhodotorula strains that can grow using raw glycerol as a carbon source. No inhibitory effects compared with analytical grade glycerol were observed. Using raw glycerol, the concordance observed between the significantly higher production of biomass and growth parameters at $15^{\circ} \mathrm{C}$ (optimum growth temperature) for the marine Rhodotorula sp. NCYC4007 and NCYC1146 could be the result of a greater glycerol bioconversion to biomass compared to glucose. Non-marine Rhodotorula (R. glutinis, $R$. mucilaginosa and $R$. gracilis) showed that glycerol can be used to produce simultaneously lipids and carotenoids; nevertheless, a glycerol concentration higher than $10 \%$ can significatively decrease the growth rate $[6,7]$. $R$. gracilis seems to be a promising candidate for lipids and carotenoids production using low-cost wastes [8], with similar yields to the present study, but at a low sodium concentration. In the present study, the marine origin of the strains used can be an advantage to cope with the osmotic stress compared with non-marine Rhodotorula. In other marine microorganisms studied to produce lipids, such as Thraustochytrium sp. AMCQS5-5, it can produce a biomass eight times greater in the medium that contains glycerol instead of glucose as a carbon source [12]. In addition, in marine yeasts such as Yarrowia lipolytica has been described that the glycerol presents a higher absorption rate than the glucose, because glycerol passes into the microbial cell by facilitated diffusion and is assimilated via either the phosphorylation or the oxidative pathway [16,27].

The production of DHA registered in strain NCYC4007 (23\% in ODW) is similar to those registered for Thraustochytrium sp. (20.4\% in ODW; [28]), Schizochytrium KH105 (22\% in ODW [29]) and Schizochytrium limacinum SR21 (19.5 at 22\% in ODW [30]). In addition to these three tested media, the maximum production of DHA was observed between 144 and $216 \mathrm{~h}$ of cultivation, a greater time as described (96 to $120 \mathrm{~h}$ ) for the Thraustochytrium sp., Schizochytrium KH105 and Schizochytrium limacinum SR21 strains.

In all carbon sources tested, a higher percent of UFAs than SFAs was observed in the fatty acids profile. Nevertheless, when raw glycerol is used, the lowest percentage of UFAs was observed. The change in the percentage of UFAs and SFAs as a result of the carbon source used has been reported in other oleaginous microorganisms such as Rhodosporidium sp. This strain observed a decrease in the percentage of PUFAs in respect to SFAs when glucose was used as a carbon source as opposed to glycerol [15]. Therefore, the raw glycerol used in this case could produce the same output of DHA as that obtained using glucose as a main carbon source from the commercial Sabouraud medium but using a substrate waste from another productive activity. This result is similar to that obtained in other marine fungoides such as Thraustochytrium sp. [31] and Aurantiochytrium sp. [32], where the total production of polyunsaturated fatty acids omega- 3 do not demonstrate significant differences between glucose and raw glycerol.

A different way to compare the results from the carbon source used could be from a nutritional point of view. Accordingly, the relationship of unsaturated fatty acids in respect to saturated ones can be calculated for strain NCYC4007. In the study, the relationship indicates that the acquired biomass obtained when raw glycerol was used presents a lower degree of unsaturation (0.5), followed by analytical grade glycerol (0.9) and, finally, glucose (1.0). This indicator of unsaturation has been associated to the oxidative stability of fatty acids [33] and, in this case, suggests that lipid contents acquired from the biomass obtained when glucose was used have a greater possibility to oxidize than lipids produced when raw glycerol was used. Thus, the acquired biomass with raw glycerol, despite having a lower unsaturation level (0.5), could present a greater stability of the PUFAs against oxidation in a bioprocess on a larger productive purposes scale than that of the biomass acquired with glucose as a carbon source (1.0).

In greater detail, the acquired profiles obtained when glucose and analytical grade glycerol were used as a carbon source highlight the presence of oleic acid (C18:1; Table 2), a 
precursor in the synthesis of polyunsaturated fatty acids belonging to the omega-3 family, such as DHA and omega-6 [34]. Meanwhile, with raw glycerol, a high production of linoleic acid was observed (C18:2, Table 2), a precursor in the synthesis of fatty acids belonging to the omega- 6 family, which can be transformed via catalysis $\Delta 15$ desaturase to $\alpha$-linoleic acid (C18:3) and, also, is a precursor to DHA synthesis [34]. These results suggest that the NCYC4007 strain could have more than one metabolic pathway for DHA synthesis, which could be induced depending on which substrate is used, according to what was observed in Schizochytrium [28], Aurantiochytrium and Thraustochytrium [35].

The TC production observed in strain NCYC1146 (19\% in ODW) is greater than described for R. mucilaginosa [13] and R. glutinis [14], corresponding to an $8 \%$ or $10 \%$ TC of ODW, respectively. The maximum production of TC in less time was observed when raw glycerol is used, similar to what was observed for the production of DHA in NCYC4007. This observation could be related with a greater activity of the biosynthesis routes due to the use of raw glycerol as a substrate as opposed to glucose. This has been described as a species of Thraustochytrids, where the polyketide synthase pathway (PKS) and that of mevalonate were involved in DHA production, used for the production of carotenoids and found to be more active in a glycerol medium to one with glucose [36].

The carotenoid pigments profile of strain NCYC1146 is similar to the profiles from Thraustochytrids strains AMCQS5-3, AMCQS5-5 [12] and ONC-T18 [36] that produce the greatest concentration of $\beta$-carotene, followed by echinenone (intermediary of 3hydroxyechinenone) and canthaxanthin. It was observed that extending the culture time of the Thraustochytrids ONC-T18 strain [37] could synthesize other xanthines such as astaxanthin due to 3-hydroxyechinenone, and the adonirrubin are precursors of this substance [37], both present in the carotenoids profile of NCYC1146 (Figure 3). To increase the cultivation time of NCYC1146 will be addressed in the future to determine if this strain can produce astaxanthin in greater cultivation times than in this study.

The Thraustochytrids have demonstrated that the DHA and carotenoid production are related across acetyl-coenzyme A (CoA) and the availability of NADPH, both used in the synthesis of these substances [14]. Therefore, the carotenoid total production and DHA as secondary metabolites of the NCYC4007 and NCYC1146 strains, respectively, would indicate that the use of raw glycerol could provide a good supply of carbon for the synthesis of said substances. In this way, DHA is synthesized from malonyl-CoA coming from AcetylCoA, which, at the same time, is a key precursor for the synthesis of acetoacetyl-CoA used for the subsequent biosynthesis of carotenoids and squalene in Thraustochytrids [14]. In this way, the simultaneous synthesis of both DHA and carotenoids in these marine Rhodotorula, using raw glycerol as a substrate, suggests that this microorganism should possess the analog biosynthetic pathways described by Thraustochytrids. Subsequent studies should clarify whether both strains also have the ability to synthesize squalene, a substance that shares the biosynthetic pathways described above and that also has commercial value, as well as DHA and carotenoids.

The carotenoid concentration with raw glycerol reached by strain NCYC 4007 is greater than observed by Pino et al. [9] for the same strain but using glucose as a carbon source. The NCYC1146 strain also synthesizes the DHA (7\% ODW of DHA at the end of the study; Figure $4 \mathrm{~b}$ ), substance of which in preliminary studies just reached $0.3 \%$ ODW when the strain was cultured with glucose. The synthesis of a secondary metabolite was observed in the cultures of the NCYC4007 (carotenoids) and NCYC1146 strains (DHA) when raw glycerol was used as a substrate, which suggests that an interconnection should exist between the biosynthesis of these two substances in these marine Rhodotorula, as observed in Thraustochytrium sp. AMCQS5-5 [12] and Thraustochytrids species [14].

To the best of our knowledge, the glucose accumulation in the culture medium when raw glycerol was used as a carbon source has not been reported in oleaginous microorganisms. Nevertheless, the appearance when raw glycerol was used could be that the excess glycerol promotes a gluconeogenesis and subsequently eliminates the synthesized glucose from the cell. To determine glucose in the culture medium could be a useful 
parameter to determine the optimum raw glycerol concentration that could be used. It has been observed that an excess of glycerol can produce an inhibition of DHA synthesis in Schizochytrium limacinum [38] and Schizochytrium limacinum SR21 [30] when used in percentages greater than $8.5 \%$ and $9 \%$, respectively, values inferior to those used in this study $(10 \%)$. In addition, excess glycerol has demonstrated the inhibition of $\beta$-carotene synthesis in Blakeslea trispora [39] and, furthermore, could restrict xanthine production, which uses $\beta$-carotene as a precursor [14].

Another interesting result to consider is the sudden increase in the intracellular phosphorus concentration from $96 \mathrm{~h}$ in NCYC4007, which is not as noticeable in NCYC1146 (Figure 4c,d). In NCYC4007, the intracellular phosphorus concentrations present a significant and strong positive correlation (semi-log; $\mathrm{R}^{2}=0.8217 ; p=0.001195$ ) with the DHA concentrations; what is suggested is that this latter could be synthesized as a phospholipid rather than as a triacylglycerol. If the DHA synthesized by NCYC4007 were in the phospholipid form, this would have a greater oxidative stability, as well as intestinal bioavailability, if used for human and animal nutrition [40]. The DHA synthesis in NCYC1146 is minor to that of NCYC4007; nonetheless, the concentrations of this substance in NCYC1146 also correlate significantly with the intracellular phosphorus of this strain (semi-log; $\mathrm{R}^{2}=0.8999$; $\left.p=8.589 \times 10^{-6}\right)$.

The intracellular cholesterol concentration in NCYC4007 (Figure 4c) presents a positive and significant relation with the intracellular phosphorus concentrations (semi-log; $\left.\mathrm{R}^{2}=0.7835 ; p=0.00092\right)$. In addition, the intracellular cholesterol presents a significant relation with the DHA concentrations $\left(\mathrm{R}^{2}=0.961 ; p=1.207 \times 10^{-7}\right)$, so this is another precedent in favor that synthesized DHA of this strain could be a phospholipid. It has been reported that cholesterol presents a high interaction with phospholipids when determined in marine species [41]. No relationship was observed between cholesterol and phosphorus in NCYC 1146; however, the main product in this strain is not DHA but carotenoids.

In respect to enzymatic activities, the increase in the MDH activity was observed in both strains and a decrease in the LDH activity during the course of the cultures (Figure $4 \mathrm{e}, \mathrm{f}$ ). The decrease of LDH activity could be associated to the use of pyruvate (anaerobic pathway) for the synthesis of the first fatty acid precursor of DHA (palmitic acid; C16:0) [42]. In addition, the MDH activity for both strains presented a strong correlation of $\log -\log$ interactions with the cell count (NCYC 4007, $\mathrm{R}^{2}=0.9596, p=0.044$ and NCYC 1146, $\mathrm{R}^{2}=0.9566, p=0.000002$ ) and live microbial biomass (NCYC 4007, $\mathrm{R}^{2}=0.8566, \mathrm{P}=0.00004$ and NCYC 1146, $\left.\mathrm{R}^{2}=0.8578, p=0.00001\right)$. These results indicate that MDH activity can be used as a proxy of the metabolic activity for both strains, similar to those described in the facultative anaerobic microorganisms [43] and microplankton organisms in the ocean [23].

\section{Conclusions}

The DHA and TC production by NCYC4007 and NCYC 1146, respectively, is greater in RGM at $15^{\circ} \mathrm{C}$. Both strains used raw glycerol as a common precursor for biosynthesis but at different rates. DHA synthetized by NCYC4007 could be a phospholipid, and NCYC 1146 could be synthetized as a canthaxanthin. The metabolic parameters suggest that the glucose accumulation in the medium and intracellular MDH activity could be used as a good proxy to adjust the optimum glycerol concentration. Finally, these strains could be used as an alternative source of PUFAs and carotenoids for human and animal nutrition, using raw glycerol for their culture.

\section{Patents}

In this work are two patent applications obtained entered into the Instituto Nacional de Propiedad Industrial (INAPI), Chile: (1) Flaked food for ornamental fish and larval stages of fish, S 1224. (2) A pelleted food rich in polyunsaturated fatty acids (PUFAs) for salmonid fingerlings, S 3471. Additionally, there was an International Patent Application through the Patent Cooperation Treaty (PCT), titled: A pelleted food rich in polyunsaturated fatty acids (PUFAs) for salmonid fingerlings, PCT/CL2018/050158. 
Author Contributions: N.L.P.-M. and R.R.G.-S. designed the experiments and analyzed the data; N.L.P.-M. performed the experiments, validation to scale the bioprocess in the bioreactor $10 \mathrm{~L}$ and statistically analyzed method; A.C. provided the analysis of the samples in HPLC for the profile of the carotenoids; B.S. provided the analysis of the samples in the chromatography of gases (GC-MM) for the profiles of the fatty acids and N.L.P.-M. and R.R.G.-S. wrote the paper. All authors have read and agreed to the published version of the manuscript.

Funding: This study could be carried out thanks to financial assistance from CONICYT ANID 21161591, CONICYT PIA PFB31 and APOYO CCTE AFB170006, Universidad de Concepción, Concepcion, Chile.

Acknowledgments: The authors would like to thank the Comercial Verdemar Ltd. Company (COVEMAR), a producer of biodiesel that facilitated raw glycerol, considered by them to be a residue. Finally, the help of Marine Organic Geochemistry Laboratory and EWOS Chile Alimentos Ltd.a., is appreciated for their collaboration in the fatty acid and carotenoid profile determinations, respectively.

Conflicts of Interest: The authors declare no conflict of interest.

\section{References}

1. Fell, J.W.; Boekhout, T.; Fonseca, A.; Scorzetti, G.; Statzell-Tallman, A. Biodiversity and systematics of basidiomycetous yeasts as determined by large-subunit rDNA D1/D2 domain sequence analysis. Int. J. Syst. Evol. Microbiol. 2000, 50, 1351-1371. [CrossRef]

2. Biswas, S.K.; Yokoyama, K.; Nishimura, K.; Miyaji, M. Molecular phylogenetics of the genus Rhodotorula and related basidiomycetous yeasts inferred from the mitochondrial cytochrome b gene. Int. J. Syst. Evol. Microbiol. 2001, 51, 1191-1199. [CrossRef]

3. Ahearn, D.G.; Roth, F.J., Jr.; Meyers, S.P. A comparative study of marine and terrestrial strains of Rhodotorula. Can. J. Microbiol. 1962, 8, 121-132. [CrossRef]

4. Jiru, T.M.; Steyn, L.; Pohl, C.; Abate, D. Production of single cell oil from cane molasses by Rhodotorula kratochvilovae (syn, Rhodosporidium kratochvilovae) SY89 as a biodiesel feedstock. Chem. Cent. J. 2018, 12, 1-7. [CrossRef]

5. Prabhu, A.A.; Gadela, R.; Bharali, B.; Deshavath, N.N.; Dasu, V.V. Development of high biomass and lipid yielding medium for newly isolated Rhodotorula mucilaginosa. Fuel 2019, 239, 874-885. [CrossRef]

6. Kot, A.M.; Błażejak, S.; Kieliszek, M.; Gientka, I.; Bryś, J. Simultaneous production of lipids and carotenoids by the red yeast Rhodotorula from waste glycerol fraction and potato wastewater. Appl. Biochem. Biotechnol. 2019, 189, 589-607. [CrossRef]

7. Kot, A.M.; Błażejak, S.; Kieliszek, M.; Gientka, I.; Bryś, J.; Reczek, L.; Pobiega, K. Effect of exogenous stress factors on the biosynthesis of carotenoids and lipids by Rhodotorula yeast strains in media containing agro-industrial waste. World J. Microbiol. Biotechnol. 2019, 35, 1-10. [CrossRef] [PubMed]

8. Kot, A.M.; Błażejak, S.; Kieliszek, M.; Gientka, I.; Piwowarek, K.; Brzezińska, R. Production of lipids and carotenoids by Rhodotorula gracilis ATCC 10788 yeast in a bioreactor using low-cost wastes. Biocatal. Agric. Biotechnol. 2020, 26, 101634. [CrossRef]

9. Pino, N.L.; Socias, C.; González, R.R. Marine fungoid producers of DHA, EPA and carotenoids from central and southern Chilean marine ecosystems. Rev. Biol. Mar. Oceanogr. 2015, 50, 507-520. [CrossRef]

10. Barra, M.; Llanos-Rivera, A.; Cruzat, F.; Pino-Maureira, N.; González-Saldía, R. The marine fungi Rhodotorula sp. (Strain CNYC4007) as a potential feed source for fish larvae Nutrition. Mar. Drugs 2017, 15, 369. [CrossRef] [PubMed]

11. Papanikolaou, S.; Aggelis, G. Modelling aspects of the biotechnological valorization of raw glycerol: Production of citric acid by Yarrowia lipolytica and 1,3- propanediol by Clostridium butyricum. J. Chem. Technol. Biotechnol. 2003, 78, 542-547. [CrossRef]

12. Gupta, A.; Singh, D.; Barrow, C.J.; Puri, M. Exploring potential use of Australian thraustochytrids for the bioconversion of glycerol to omega-3 and carotenoids production. Biochem. Eng. J. 2013, 78, 11-17. [CrossRef]

13. Aksu, Z.; Eren, A.T. Carotenoids production by the yeast Rhodotorula mucilaginosa: Use of agricultural wastes as a carbon source. Process Biochem. 2005, 40, 2985-2991. [CrossRef]

14. Saenge, C.; Cheirsilp, B.; Suksaroge, T.T.; Bourtoom, T. Potential use of oleaginous red yeast Rhodotorula glutinis for the bioconversion of crude glycerol from biodiesel plant to lipids and carotenoids. Process Biochem. 2011, 46, 210-218. [CrossRef]

15. Xu, J.; Zhao, X.; Wang, W.; Du, W.; Liu, D. Microbial conversion of biodiesel byproduct glycerol to triacylglycerols by oleaginous yeast Rhodosporidium toruloides and the individual effect of some impurities on lipid production. Biochem. Eng. J. 2012, 65, 30-36. [CrossRef]

16. Makri, A.; Fakas, S.; Aggelis, G. Metabolic activities of biotechnological interest in Yarrowia lipolytica grown on glycerol in repeated batch cultures. Bioresour. Technol. 2010, 101, 2351-2358. [CrossRef]

17. Mączka, W.; Wińska, K.; Grabarczyk, M.; Żarowska, B. Biotransformation of $\alpha$-Acetylbutyrolactone in Rhodotorula Strains. Int. J. Mol. Sci. 2018, 19, 2106. [CrossRef] [PubMed]

18. Honda, D.; Yokochi, T.; Nakahara, T.; Raghukumar, S.; Nakagiri, A.; Schaumann, K.; Higashihara, T. Molecular phylogeny of labyrinthulids and thraustochytrids based on the sequencing of 18S ribosomal RNA gene. J. Eukaryot. Microbiol. 1999, 46, 637-647. [CrossRef] [PubMed] 
19. Rodher, A. Determinación de carotenoids. Rev. Agroquím. Tecnol. Aliment. 1966, 6, 24-27.

20. Bligh, E.G.; Dyer, W.J. A rapid method for total lipid extraction and purification. Can. J. Biochem. Physiol. 1959, 37, 911-917. [CrossRef]

21. Christie, W.W. The preparation of derivate of fatty acids. In Gas Chromatography and Lipids: A Practical Guide; Christie, W.W., Ed.; The Oily Press: Bridgwater, UK, 1989; pp. 36-39.

22. Tolosa, I.; Vescovali, I.; Leblond, N.; Marty, J.C.; de Mora, S.; Prieur, L. Distribution of pigments and fatty acids biomarkers in particulate matter from the frontal structure of the Alboran Sea (SW Mediterranean Sea). Mar. Chem. 2004, 88, 103-125. [CrossRef]

23. Holm-Hansen, O; Both, C. The measurement of adenosine triphosphate in the ocean and its ecological significance. Limnol. Oceanogr. 1966, 11, 510-519. [CrossRef]

24. González, R.R.; Quiñones, R.A. Common catabolic enzyme patterns in a microplankton community of the Humboldt Current System off northern and central-south Chile: Malate dehydrogenase activity as an index of water-column metabolism in an oxygen minimum zone. Deep-Sea Res. Part II Top. Stud. Oceanogr. 2009, 56, 1095-1104. [CrossRef]

25. Schneider, W.; Donoso, D.; Garcés-Vargas, J.; Escribano, R. Water-column cooling and sea surface salinity increase in the upwelling region off central-south Chile driven by a poleward displacement of the South Pacific High. Prog. Oceanogr. 2017, 151, 38-48. [CrossRef]

26. Pérez-Santos, I.; Garcés-Vargas, J.; Schneider, W.; Ross, L.; Parra, S.; Valle-Levinson, A. Double-diffusive layering and mixing in Patagonian fjords. Prog. Oceanogr. 2014, 129, 35-49. [CrossRef]

27. Morgunov, I.G.; Kamzolova, S.V.; Lunina, J.N. The citric acid production from raw glycerol by Yarrowia lipolytica yeast and its regulation. Appl. Microbiol. Biotechnol. 2013, 97, 7387-7397. [CrossRef] [PubMed]

28. Metz, J.G.; Roessler, P.; Facciotti, D.; Levering, C.; Dittrich, F.; Lassner, M.; Yazawa, K. Production of polyunsaturated fatty acids by polyketide synthases in both prokaryotes and eukaryotes. Science 2001, 293, 290-293. [CrossRef] [PubMed]

29. Yamasaki, T.; Aki, T.; Mori, Y.; Yamamoto, T.; Shinozaki, M.; Kawamoto, S.; Ono, K. Nutritional enrichment of larval fish feed with thraustochytrid producing polyunsaturated fatty acids and xanthophylls. J. Biosci. Bioeng. 2007, 104, 200-206. [CrossRef] [PubMed]

30. Chi, Z.; Pyle, D.; Wen, Z.; Frear, C.; Chen, S. A laboratory study of producing docosahexaenoic acid from biodiesel-waste glycerol by microalgal fermentation. Process Biochem. 2007, 42, 1537-1545. [CrossRef]

31. Avalos, J.; Nordzieke, S.; Parra, O.; Pardo-Medina, J.; Limón, M.C. Carotenoid production by filamentous fungi and yeasts. In Biotechnology of Yeasts and Filamentous Fungi; Sibirny, A.A., Ed.; Springer: Berlin, Germany, 2017; pp. $225-279$.

32. Chang, K.J.L.; Dumsday, G.; Nichols, P.D.; Dunstan, G.A.; Blackburn, S.I.; Koutoulis, A. High cell density cultivation of a novel Aurantiochytrium sp. strain TC 20 in a fed-batch system using glycerol to produce feedstock for biodiesel and omega-3 oils. Appl. Microbiol. Biotechnol. 2013, 97, 6907-6918. [CrossRef]

33. Hernandez, A.G.D. Nutrition treatise: Composition and nutritional quality of foods Tome II., Ed. Med. Panam. $2010,2,812$.

34. Béligon, V.; Christophe, G.; Fontanille, P.; Larroche, C. Microbial lipids as potential source to food supplements. Curr. Opin. Food Sci. 2016, 7, 35-42. [CrossRef]

35. Nagano, N.; Sakaguchi, K.; Taoka, Y.; Okita, Y.; Honda, D.; Ito, M.; Hayashi, M. Detection of genes involved in fatty acid elongation and desaturation in thraustochytrid marine eukaryotes. J. Oleo Sci. 2011, 60, 475-481. [CrossRef]

36. Aasen, I.M.; Ertesvåg, H.; Heggeset, T.M.B.; Liu, B.; Brautaset, T.; Vadstein, O.; Ellingsen, T.E. Thraustochytrids as production organisms for docosahexaenoic acid (DHA), squalene, and carotenoids. Appl. Microbiol. Biotechnol. 2016, 100, 4309-4321. [CrossRef]

37. Armenta, R.E.; Burja, A.; Radianingtyas, H.; Barrow, C.J. Critical assessment of various techniques for the extraction of carotenoids and co-enzyme Q10 from the Thraustochytrid strain ONC-T18. J. Agric. Food Chem. 2006, 54, 9752-9758. [CrossRef]

38. Yokochi, T.; Honda, D.; Higashihara, T.; Nakahara, T. Optimization of docosahexaenoic acid production by Schizochytrium limacinum SR21. Appl. Microbiol. Biotechnol. 1998, 49, 72-76. [CrossRef]

39. Mantzouridou, F.; Naziri, E.; Tsimidou, M.Z. Industrial glycerol as a supplementary carbon source in the production of $\beta$-carotene by Blakeslea trispora. J. Agric. Food Chem. 2008, 56, 2668-2675. [CrossRef]

40. Henna, L.; Nielsen, N.; Timm-Heinrich, M.; Jacobsen, C. Oxidative stability of marine phospholipids in the liposomal form and their applications. Lipids 2011, 46, 3-23. [CrossRef] [PubMed]

41. Valenzuela, A.; Valenzuela, R.; Sanhueza, J.; de la Barra, F.; Morales, G. Fosfolípidos de origen marino: Una nueva alternativa para la suplementación con ácidos grasos omega-3. Rev. Chil. Nutr. 2014, 41, 433-438. [CrossRef]

42. Christophe, G.; Kumar, V.; Nouaille, R.; Gaudet, G.; Fontanille, P.; Pandey, A.; Soccol, C.R.; Larroche, C. Recent developments in microbial oils production: A possible alternative to vegetable oils for biodiesel without competition with human food? Braz. Arch. Biol. Technol. 2012, 55, 29-46. [CrossRef]

43. Fenchel, T.; Finlay, B.J. Ecology and Evolution in Anoxic Worlds; Oxford University Press: Oxford, UK, 1995; 276p. 